\title{
Investigation of microstructural and mechanical properties of AA1050-AZ91D dissimilar friction stir welding
}

\author{
O. Kayode ${ }^{1}$, E.T. Akinlabi2 \\ ${ }^{1}$ Department of Mechanical Engineering Science, University of Johannesburg, 2006 Auckland Park Kingsway, Johannesburg, South Africa \\ Phone: +27747010070 \\ ${ }_{2}^{2}$ Pan African University for Life and Earth Sciences (PAULESI), Ibadan, 200284, Nigeria
}

\begin{abstract}
Joining of aluminium and magnesium alloys frequently pose significant challenges to the extent where joining may seem impossible, due to differences in the physical, metallurgical, and chemical properties of the materials. Friction stir welding is a solid-state welding technique which uses a non-consumable tool to join metals. This study examines the dissimilar friction stir welding of $3 \mathrm{~mm}$ thick AA1050 and AZ91D alloy sheets. Successful defect-free joints were achieved at rotational speeds of $400 \mathrm{rpm}$ and $600 \mathrm{rpm}$, and a constant traverse speed of 50 $\mathrm{mm} / \mathrm{min}$. The metallurgical investigations used to characterize the microstructure of the welds are optical microscopy (OM), scanning electron microscope (SEM) and X-ray diffraction (XRD). The microstructures of the samples show distinct morphology attributed to their different rotational speeds. However, $\mathrm{Al}_{3} \mathrm{Mg}_{2}$ intermetallics (IMCs) phase was detected in the white bands present in both weld samples. The IMCs were formed through solid-state diffusion. The mechanical properties characterizations includes the microhardness profiles and tensile testing. The variation in the rotational speeds do not have a significant effect on the microhardness distribution of the weld samples. The tensile strength of the dissimilar weld improved substantially with the presence of an interpenetration feature (IPF).
\end{abstract}

ARTICLE HISTORY

Received: $3^{\text {rd }}$ Aug 2020

Revised: $6^{\text {th }}$ Oct 2020

Accepted: 17 $7^{\text {th }}$ Mar 2021

\section{KEYWORDS}

Friction stir welding;

aluminium alloy;

magnesium alloy;

dissimilar welding;

microstructural analysis;

mechanical characterization.

\section{INTRODUCTION}

There has been recent increase in demand for innovative lightweight structures in the transportation industry for safety, efficiency, fuel economy and attaining strict emissions reduction regulations, especially in the automobile and aerospace industries [1,2]. Most automobile and aircraft manufacturers have begun to shift their research and development focus to the use of lightweight structures towards meeting the strict $\mathrm{CO}_{2}$ regulations. For example, the Multi-Material Lightweight Vehicle (MMLV) Program by the United States of America (USA) Department of Energy in collaboration with Magna International and Ford Motor Company, showed a 50\% weight-reduction potential using multi-materials [3]. The reduction in automobile and aircraft weight has been the most critical measure of design efficiency assessment in these industries as $\mathrm{CO}_{2}$ emission is directly proportional to fuel consumption and efficiency [4]. This continuous demand and strive for weight reduction have led to the increasing trend of substituting existing materials with alternative existing or newly developed materials with lower density but same, close or improved mechanical performance and requirements of the original components.

Among the various alternative lightweight materials, joining of magnesium $(\mathrm{Mg})$ to aluminum $(\mathrm{Al})$ in proper portion is an alternative that has been considered as suitable potential for mitigating the challenges of weight reduction in the automobile and aircraft manufacture. Even though $\mathrm{Mg}$ alloys are not as strong as aluminium alloys, they are significantly lighter and usually compete with aluminium alloys in structural applications [5]. However, joining $\mathrm{Mg}$ alloys to Al alloys has posed various barriers and challenges such as availability of materials, surface treatment issues, bad corrosion resistance, and most importantly the suitable joining technology. The major problem encountered with the welding of Al and $\mathrm{Mg}$ alloys is the formation of liquation and intermetallics [6]. Mansoor et al [7] reported that the solid-state welding processes are more promising for joining $\mathrm{Mg}$ and $\mathrm{Al}$ alloys than the fusion based welding processes because they provide controllable heat inputs and reaction times. It has been established that friction stir welding (FSW) is an appropriate joining technique to join these dissimilar materials and reduce the effects of IMCs [8]. FSW is a solid-state joining technique developed at The Welding Institute (TWI) of the United Kingdom (UK) in 1991 [9]. A schematic of the process is shown in Figure 1. However, full description and details of this technique has been widely reported in various literatures [8-11]. 


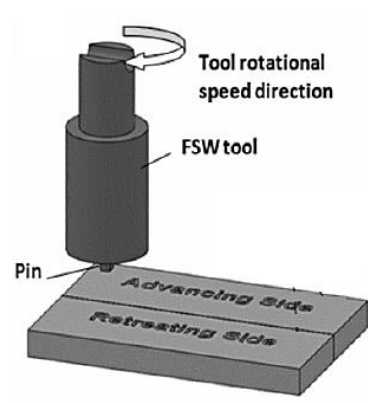

Step 1

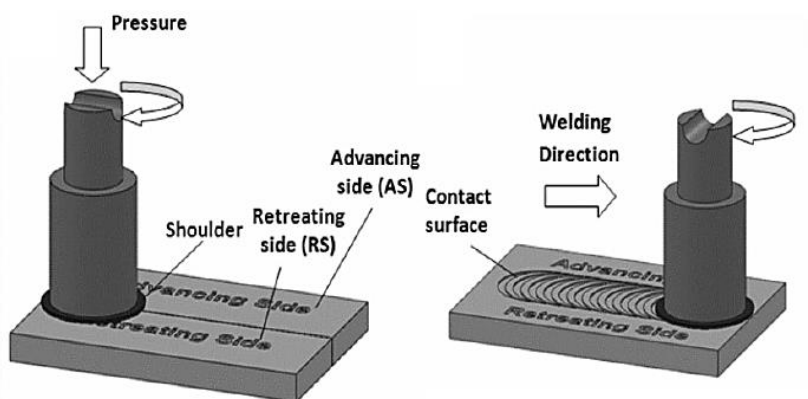

Step 2

Step 3

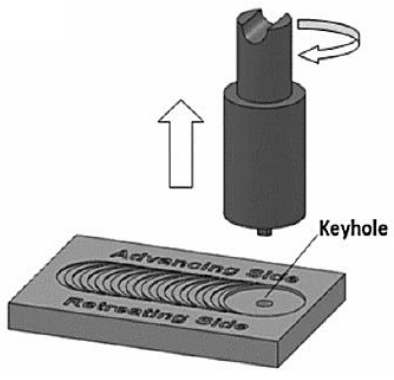

Step 4

Figure 1. Schematics of the friction stir welding process

A review of literature shows that researchers have employed FSW to join dissimilar $\mathrm{Mg}$ and $\mathrm{Al}$ alloys; and have investigated the welds metallurgical and mechanical properties such as micro-hardness and tensile properties. Yamamoto et al [12] reported that formation of IMCs occurred through react diffusion during the FSW AA5083 and AZ31 alloys because the temperature was more than $376.67{ }^{\circ} \mathrm{C}$, which is the eutectic reaction temperature of $\mathrm{Mg}$ and $\mathrm{Al}$ alloys. Furthermore, the IMCs grows with the increase in tool offset which in turn causes a decrease in the joint tensile strength. Although Sato et al [13] recorded a defect-free weld when they joined AA1050 and AZ31 using FSW, they reported a similar observation that $\mathrm{Al}_{12} \mathrm{Mg}_{17} \mathrm{IMCs}$ was formed by constitutional liquation resulting from elevated temperature above $389.44{ }^{\circ} \mathrm{C}$. Fu et al [14] also reported the formation of IMCs due to constitutional liquation when they joined AA6061T6 and AZ31B alloys. The authors reported that a defect-free weld with a homogenous intermixing and high tensile properties was achieved when the $\mathrm{Mg}$ alloy was positioned on the advancing side (AS) with a $0.3 \mathrm{~mm}$ tool offset to the $\mathrm{Mg}$ alloy, but a tool offset to the $\mathrm{Al}$ alloy resulted into occurrence of defects.

Dorbane et al [15] gave a contrary report that the placement of the Al alloy on the AS during the FSW of AA6061T6 and AZ31B alloys results in a better weld quality and placing the Al alloy on the retreating side (RS) causes defects such as surface galling and voids. However, they also concluded that the fracture of the weld joints initiated in the IMCs present between the $\mathrm{Al} / \mathrm{Mg}$ joint interface. Somasekharan and Murr [16] reported that there was a clear demarcation band on the RS of the weld when they joined AA6061-T6 and AZ91D alloys using FSW. The authors claimed that the temperature attained in the weld is within the range of the $\mathrm{Mg}$ alloy solidus temperature and the demarcation band caused a variation in the hardness values in the stir zone. These studies shows the formation of IMCs during the FSW of Mg and Al alloys and their detrimental effect on the mechanical properties. However, some studies have also shown the elimination of IMCs when $\mathrm{Mg}$ and $\mathrm{Al}$ dissimilar alloys were joined using FSW. Masoudian et al [17] joined AZ31B and AA6061-T6 by placing the Mg and Al alloy on the RS and AS respectively with no tool offset. They recorded an uneven microhardness distribution and a tensile strength up to about $76 \%$ of the Al alloy with no IMCs formation. Kwon et al [18] also recorded a joint tensile strength of about $66 \%$ of the $\mathrm{Al}$ alloy with no formation of IMCs when they joined $\mathrm{Al}$ A5052P-O and AZ31B-O dissimilar alloys. Yan et al [19] reported that there was a stir zone with complex flow pattern and intercalation lamellae characteristics but interestingly with an absence of IMCs when they joined AA5052 and AZ31B alloys using FSW. They reported that there was an uneven microhardness distribution with the maximum hardness value in the middle of the stir zone.

Although there is a recent focus on the FSW of Mg and $\mathrm{Al}$ alloys, to the best of the authors' knowledge, there is still limited studies on the various $\mathrm{Mg}$ and $\mathrm{Al}$ alloys combination, and there is no article on the dissimilar joining of AZ91D and AA1050. It was observed that most studies focus on the AZ Mg family and 6XXX series Al alloy. This is unsurprising because alloyed aluminium metals are mostly utilized in the transportation industries due to their improved strength. However, the Al 1XXX series offers the best corrosion resistance among all Al alloy series groups. The AZ family Mg alloys are the most commonly used magnesium die casting alloy. Hence, joining these dissimilar materials could have potential applications in new structural and components designs in the transportation industry. This present work investigates the microstructural and mechanical properties of the dissimilar friction stir welding of $1050 \mathrm{Al}$ alloy and AZ91D Mg alloy, to contribute to the existing literature on the FSW of aluminium and magnesium alloys.

\section{METHODS AND MATERIALS}

The nominal chemical compositions of AA1050 Al alloy and AZ91 Mg alloy plates used in this study are listed in Table 1 and Table 2 respectively. The mechanical properties of the alloys are presented in Table 3. The welding experiments were conducted on a 2 Ton linear numerical controlled FSW machine, shown in Figure 2.

Table 1. Chemical composition of AA1050

\begin{tabular}{cccccccccc}
\hline Element & $\mathrm{Si}$ & $\mathrm{Fe}$ & $\mathrm{Cu}$ & $\mathrm{Na}$ & $\mathrm{Ni}$ & $\mathrm{K}$ & $\mathrm{Zn}$ & $\mathrm{Ga}$ & $\mathrm{Al}$ \\
Weight Percentage $(\%)$ & 0.15 & 0.27 & 0.02 & 0.03 & 0.02 & 0.02 & 0.02 & 0.02 & 99.47 \\
\hline
\end{tabular}


Table 2. Chemical composition of AZ91D

\begin{tabular}{cccccccccc}
\hline Element & $\mathrm{Si}$ & $\mathrm{Fe}$ & $\mathrm{Mn}$ & $\mathrm{Al}$ & $\mathrm{Na}$ & $\mathrm{K}$ & $\mathrm{Zn}$ & $\mathrm{Ca}$ & $\mathrm{Mg}$ \\
Weight Percentage (\%) & 0.54 & 0.05 & 0.24 & 9.91 & 0.11 & 0.34 & 0.90 & 0.12 & 87.04 \\
\hline
\end{tabular}

Table 3. Mechanical properties of AA1050 and AZ91D

\begin{tabular}{lcc}
\hline Mechanical Properties & AA1050 & AZ91D \\
\hline Ultimate Tensile strength (MPa) & 126 & 117 \\
Yield Strength (MPa) & 103 & 110 \\
Elongation (\%) & 13 & 7 \\
Hardness (HV) & 50 & 72 \\
Tensile Modulus (GPa) & 69 & 44.8 \\
Poisson Ratio & 0.33 & 0.35 \\
\hline
\end{tabular}

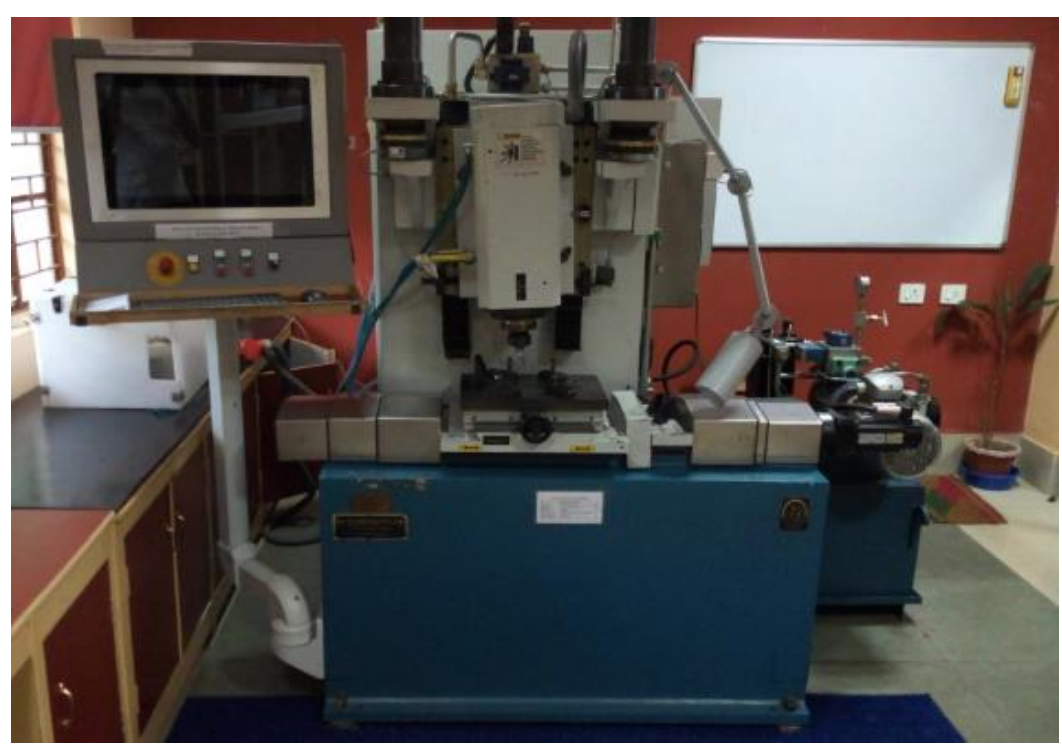

Figure 2. Friction stir welding machine used for joining AA1050 and AZ91D alloys

The dimension of the test coupon for each plate was $300 \times 120 \times 3 \mathrm{~mm}$ as shown in Figure 3a. The welding process was carried out using a non-consumable tool with a square pin profile as shown in Figure $3 \mathrm{~b}$. The tool material is H13 hot-working tool steel. The tool have a flat shoulder surfac. A pin length of $2.4 \mathrm{~mm}$, square pin diameter of $5 \mathrm{~mm}$, shoulder diameter of $15 \mathrm{~mm}$ and a tool pin plunge depth of $0.2 \mathrm{~mm}$ was used in both experiments. The tool pin was plunged at an offset $0.7 \mathrm{~mm}$ towards the $\mathrm{Mg}$ alloy at a tilt angle of $2.5^{\circ}$. The $\mathrm{H} 13$ hot-working tool steel has a melting point of $1427{ }^{\circ} \mathrm{C}$ and satisfies the required characteristics of an appropriate tool suitable for dissimilar FSW of $\mathrm{Al}$ and $\mathrm{Mg}$ alloys. Rotational speeds of 400 and $600 \mathrm{rpm}$ and constant traverse speed of $50 \mathrm{~mm} / \mathrm{min}$ were employed. It is worthy to note that these parameters are the ones that produced successful joints out of the preliminary experiments carried out from an array of weld matrix (rotational speeds of 400, 600, 800, 1000 and $1200 \mathrm{rpm}$; and traverse speeeds of 50, $100 \mathrm{and} 150 \mathrm{~mm} / \mathrm{min}$ ). The Mg alloy was placed on the AS while the Al alloy was placed on the RS of the weld. The tool was offset $0.7 \mathrm{~mm}$ to the AS of the welds before it was inserted into the joint to carry out the welding along the traverse direction. After successfully joining the dissimilar materials, a cross-section of the stir zone of size $30 \times 10 \times 3 \mathrm{~mm}$ was cut perpendicular to the welding direction with a wire-cut electric discharge machining (EDM) and prepared according to standard metallographic procedures. 
(b)

(a)
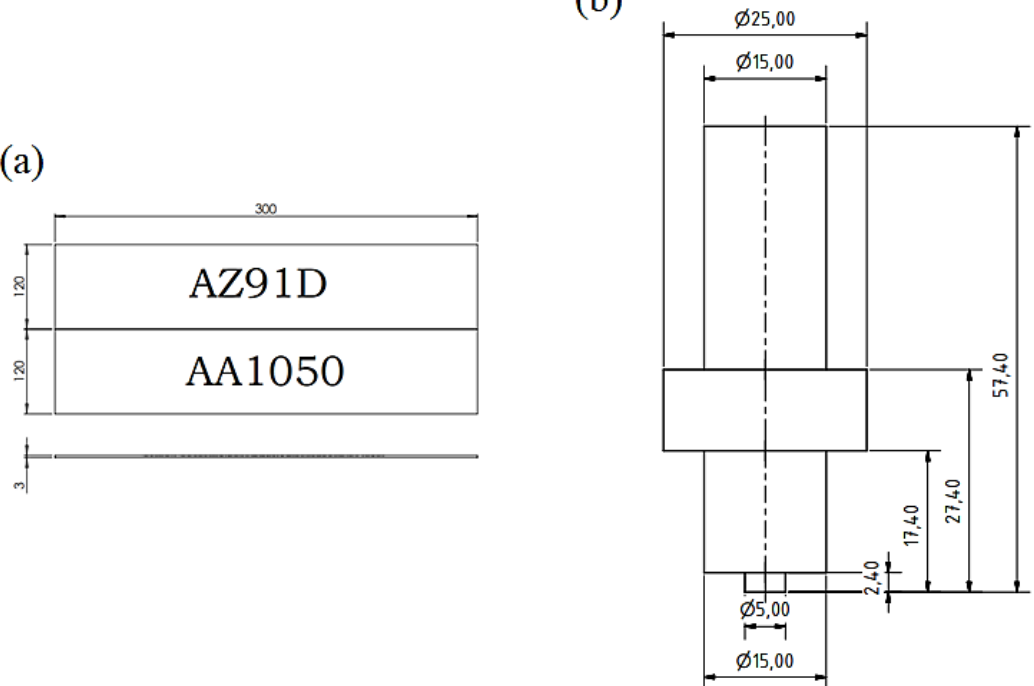

Figure 3. Schematic diagrams of: (a) Specimens dimension and arrangement and (b) FSW tool

The metallographic techniques employed entails grinding of the weld samples with silicon carbide papers with grades between 220 - 1200 grits, with water as the coolant necessary to prevent overheating of the weld samples and possible fire hazard during the grinding process as usually associated with $\mathrm{Mg}$ dust. The surface of the samples were constantly cleansed with acetone to reduce the effects of water on the $\mathrm{Mg}$ side of the weld. After this, the samples were polished with a non-drying colloidal silica suspension and a polishing cloth and again repeatedly cleansed with acetone to avoid contamination of the $\mathrm{Mg}$ side. The samples were then firstly etched in a picral solution of $10 \mathrm{~mm}$ acetic acid, $10 \mathrm{ml}$ distilled water and $4.2 \mathrm{~g}$ picral acid in $100 \mathrm{ml}$ ethanol for 6 seconds to the reveal the $\mathrm{Mg}$ alloy side microstructure. Secondly, the samples were immersed in a solution of $20 \mathrm{~g} \mathrm{NaOH}$ in $100 \mathrm{ml}$ distilled water for 40 seconds and lastly, the samples were dipped in a Weck's reagent solution comprising of $4 \mathrm{~g} \mathrm{KMnO} 4$ and $2 \mathrm{~g} \mathrm{NaOH}$ in $100 \mathrm{ml}$ distilled water for 10 seconds. Three-step etching procedure has been previously used to reveal the lamellar shear bands and $\mathrm{Al}_{3} \mathrm{Mg}_{2}$ and $\mathrm{Al}_{12} \mathrm{Mg}_{17}$ IMCs phases in dissimilar FSW of $\mathrm{Mg}$ and $\mathrm{Al}$ alloys [20, 21].

The samples were rinsed thoroughly with distilled water, cleansed with acetone, and observed with an Olympus BX51M microscope to reveal the microstructure. This specimens of the same size as those used for microstructural investigations were cut across the stir zone for microhardness measurements. The measurements were conducted according to ASTM 384-05a guidelines [22]. The indentations were made with a load of $200 \mathrm{~g}$ and dwell time of 15 seconds at a constant interval of $1 \mathrm{~mm}$ in a row in the mid-thickness, throughout the cross-section of the weld sample to cover all the weld microstructural zones. For the tensile testing, the specimens were prepared according to ASTM E8 guidelines [23] and tested using a $250 \mathrm{kN}$ capacity Zwick Roell static tensile testing machine at a constant crosshead displacement of $1 \mathrm{~mm} / \mathrm{min}$. Three tensile specimens were prepared and tested for each welding condition and the average of the tensile values of the three specimens was calculated as the representative UTS of each weld samples. A Zeiss Sigma field emission scanning electron microscope (FESEM) was employed to characterize and study the morphology of the fracture surface of the tensile test specimens. Identification and analysis of the IMCs phases in the weld samples were done using a Rigaku ZSR Primus II XRD machine with an X-ray tube of optical-above geometry that uses a voltage of $40 \mathrm{Kv}$ and current of $30 \mathrm{~mA}$.

\section{RESULTS}

\section{Weld Appearance and Microstructural Characterization}

The welds morphology presented in Figure 4 shows regular surfaces with spaced semicircular bands and absence of identifiable defects during visual inspection. Both welds displayed excellent appearance with no visible structural defects at the weld surface and weld root. The microstructural images of the joints and respective areas of interest in the stir zones, obtained through optical microscopy $(\mathrm{OM})$, are presented in Figure 5 and Figure 6 . It is worthy to take note that the $\mathrm{Mg}$ alloy is on the AS (right-hand side) while Al alloy are located on the RS (left-hand side) in all the welds. The welds joined at $600 \mathrm{rpm}$ and $400 \mathrm{rpm}$ are subsequently referred to as FSW1 and FSW2 respectively. Both weld samples shows a joint interface with unique characteristics which are significantly different from the typical microstructure mostly obtained for similar FSW of the individual materials. The major stir zone found in the similar FSW of the alloys are elliptical and basin-shaped nuggets with onion-ring structure [24, 25]. The dissimilar welds exhibits different material flow and mechanical intermixing in their joint interface due to the difference in their material properties, melting temperature and deformation rates. As a result, they tend not to display the four typical distinct regions (parent material, heat affected zone, thermomechanical affected zone and stir zone) as usually observed in the FSW of similar alloys because the stirring of the dissimilar alloys at the centre of the weld may not be sufficient to obtain the required mixing 
[11]. To further understand the complex stir zone of these dissimilar structures, Shah et al [8] has systematically categorized the usual joint interface of FSW of $\mathrm{Mg}$ and $\mathrm{Al}$ alloys based on the cross-sectional bond interface into three types, namely: distinct boundary, lamellae structure with distinct boundary and complex intercalated lamellae structure. These interfaces occur due to negligible mixing between the dissimilar alloys, enhanced material flow and intermixing between both alloys, and presence of an observable interpenetrating feature (IPF), respectively.
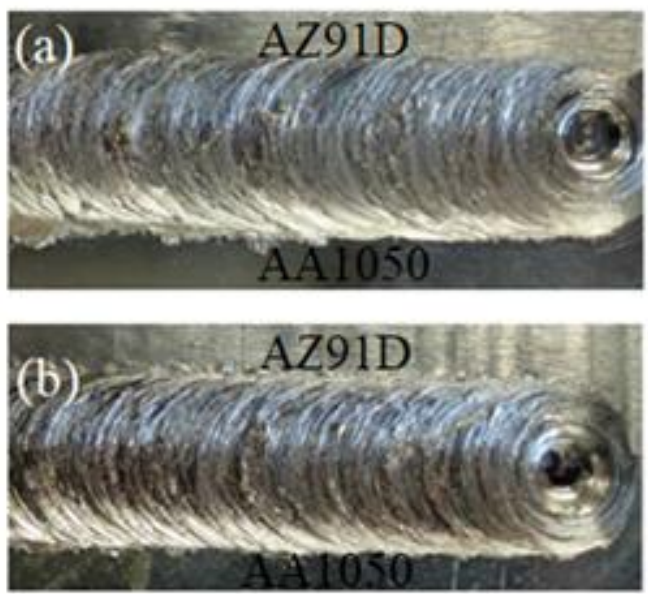

Figure 4. Top surface appearance of dissimilar AA1050-AZ91D welds at: (a) 600rpm and (b) 400rpm

Both FSW1 and FSW2 show a complex intercalated microstructure with absence of visually observable cracks, porosity and liquation, although the weld joined at a rotational speed of $600 \mathrm{rpm}$ shows a more complex microstructure than that joined at $400 \mathrm{rpm}$. Several researchers have also reported similar intercalated structures in their studies on FSW of $\mathrm{Mg}$ and $\mathrm{Al}$ alloys [17, 26-28].

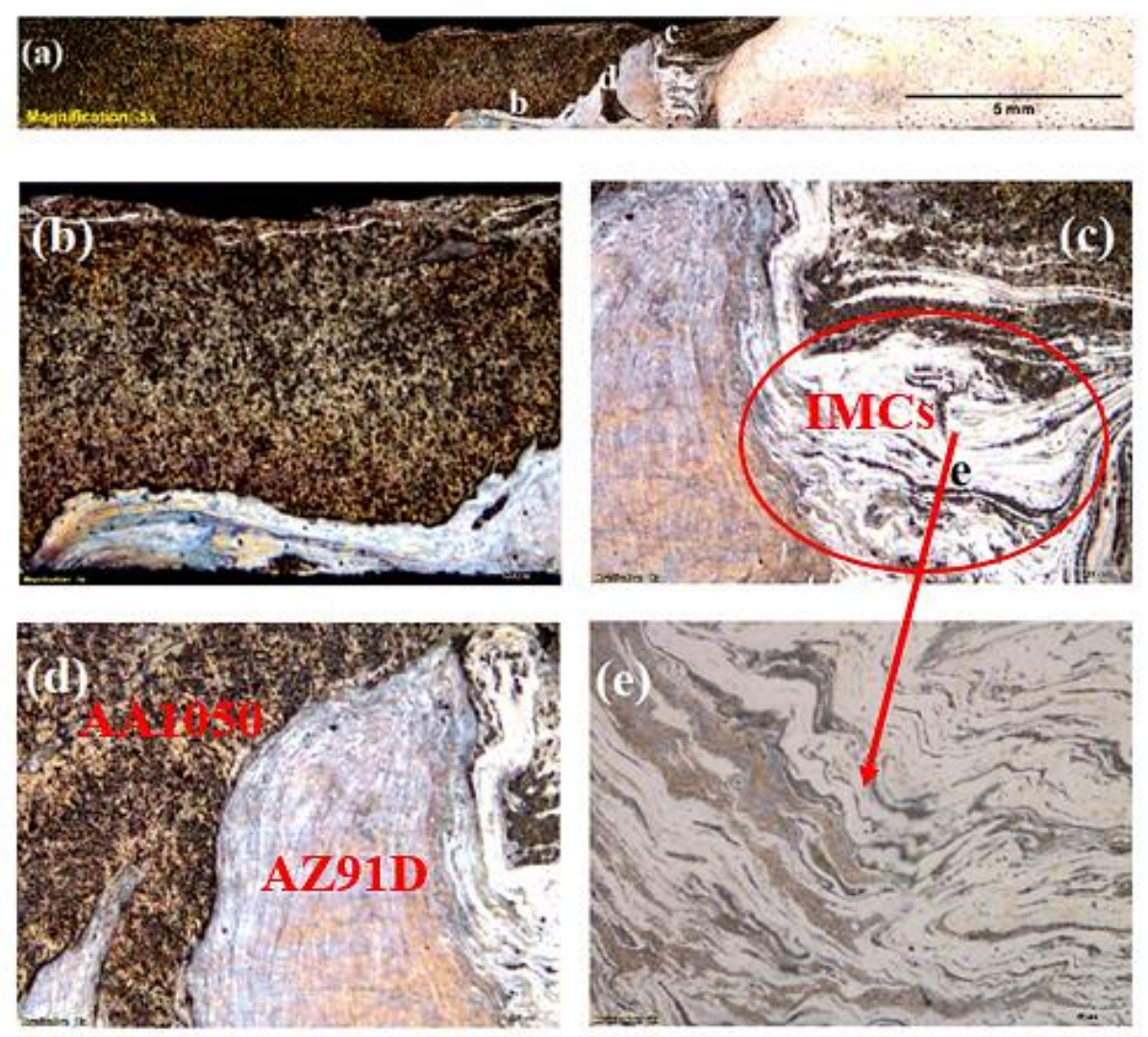

Figure 5. Weld map of FSW1 in (a), point of interest in stir zone shown in (b) - (d). Magnified image of (c) in (e) 

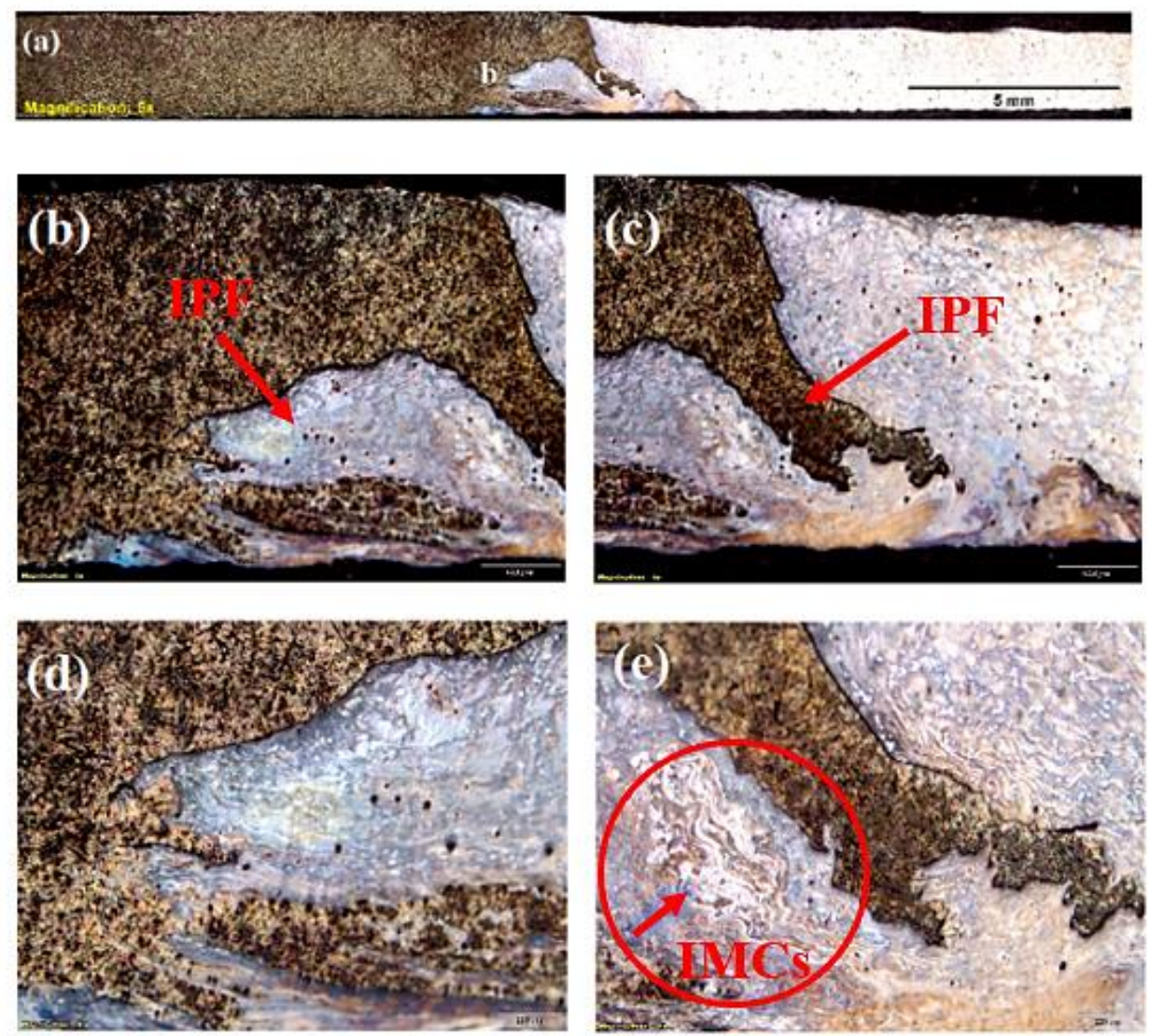

Figure 6. Weld map of FSW2 in (a), point of interest in stir zone shown in (b) and (c). Magnified view of: (b) in (d), and (c) in (e)

The stir zone in FSW1 (Figure 5) display an intermittent lamellar-like shear band structure with a good material flow and intermixing. On the other hand, there is no observable nugget structure in the stir zone of FSW2 (Figure 6). However, a good islanding and interlocking characteristic of an interpenetrating feature can be clearly observed in the upper and lower sections of the stir zone of the latter weld sample. Due to the complex material flow and tool offsetting, the $\mathrm{Mg}$ alloy is accumulated and deposited more in the stir zone of FSW 1, thereby exhibiting a skewed stir zone. There was a good dynamic recrystallization in this region as a result of the heat generated between the tool and workpiece materials, and additionally from the high strain rate. Based on the clear demarcation exhibited by the stir zone, this zone can be divided into three observable regions.

The first region on the left-hand side of the weld is presented in Figure 5(b). This region shows a significant flow of the plasticized $\mathrm{Mg}$ alloy into the bottom part of the $\mathrm{Al}$ alloy on the RS. It can be clearly observed that there is a deviation of some $\mathrm{Mg}$ alloy from the tool pin rotation path during the welding process. This phenomena is still very much ambiguous due to the complexity of the stir zone microstructure; however it contributes to the increase in joint interface length, which in turn helps to increase the area of metallurgical bonding. It has been reported that there is a possibility for achieving an improved tensile strength with increase in joint interface length and complexity [29].

The second region which is the area in the middle of the stir zone is presented in Figure 5(c). This region exhibit an extreme extrusion of AZ91D in the stir zone, somehow forming an IPF replica with refined grain size compared to the $\mathrm{Mg}$ parent material. Similar to the first region, the grain refinement could be attributed to dynamic recrystallization while the IPF replica creates an interlocking evident in both the top and bottom part of the stir zone. It can be deduced from the material flow pattern that most of the material flow results from tool pin which was able to transfer the plasticized AZ91D from the front to the back of the pin. It can be clearly observed that the AZ91D alloy is deposited at the wake of the tool pin just as it's about to make a transition in its rotation from the RS to AS. The plasticized AA1050 alloy is then transported in the stir zone in a collective effort with the tool shoulder. The chaotic solid-state intercalated flow pattern characterized by swirls and vortexes and massive thick white bands are formed as a result of the reaction and intermixing of the extruded AZ91D closer to the AS and transported AAA1050 in the stir zone. The demarcation between the second and third regions is clearly shown in Figure 5(c). The third region can be further subdivided into upper and lower areas based on their microstructural characteristics. The upper area consist of the AA1050 alloy and thin white bands while the lower area constitutes a vortex where there is interpenetration between AZ91D and AA1050 alloys. Figure 5(d) shows that the $\mathrm{Mg}$ and $\mathrm{Al}$ alloys are swirled together to form a complex intermixing pattern, showcasing the presence of thick white bands in the lower area.

Figure 6(b) presents the extrusion of AZ91D into AA1050 in FSW2 while the islanding of AA1050 into AZ91D in the sample is shown in Figure 6(c). it could be clearly observed that there is less intermixing in FSW2 compared to FSW1. 
However, there was more bulk material flow in both AS and RS of FSW2 than that in FSW1. This excellent material flow caused the formation of IPF and helped to establish a longer joint interface length than FSW1. To have a better overview of these microstructure, magnified images of the $\mathrm{Mg}$ and $\mathrm{Al}$ islands described are presented in Figure 6(d) and (e) respectively. This magnified images revealed the absence of thick IMCs layer but aid in visualizing the presence of a swirl-like white band of microscopic scale at the beginning of the $\mathrm{Mg}$ island close to the edge of the Al alloy IPF (indicated with an arrow). The combination of lower rotational speed and travel speeds employed in joining FSW2 causes less materials intermixing and absence of thick IMCs layer and white bands due to less softening and lower peak temperature during the welding process. Firouzdor and Kou [20] and Chen and Nakata [30] have reported that lowering the heat input during FSW of Mg and $\mathrm{Al}$ alloys causes a significant reduction in IMCs. The symmetrical orientation and identical length and thickness of the Mg and Al IPF resulting from their islands contributes to the tensile strength of the weld. Firouzdor and Kou [20] reported that a thick IPF and long joint interface length enhances mechanical interlocking and metallurgical bonding. Furthermore, it is worthy to note that the interpenetration of the dispersed fragment of AA1050 into the AZ91D alloy at the bottom region of the stir zone is a morphological feature that's expected to improve the tensile strength of the joint by creating a complex microstructure and interlocking.

The SEM images of areas of interest in stir zones of FSW1 and FSW2 with their corresponding EDX analysis are presented in Figure 7 and Figure 8 respectively. The analysis of FSW1 shows that the upper part of the third region of the stir zone and the swirl and vortex as described above exhibits high percentages of $\mathrm{Al}$ and $\mathrm{Mg}$ alloys clustered in these region, suggesting the presence of IMCs in the white bands observed in this weld sample. The SEM images of FSW2 shows that the $\mathrm{Mg}$ island predominantly contains $\mathrm{Mg}$ alloy while that of the Al shows that it contains $\mathrm{Al}$ alloy with a high affinity with its silicon composition. These white bands have been identified as IMCs through XRD analysis. The X-ray diffraction pattern of the stir zones of FSW1 and FSW2 are presented in Figure 9. The spectrums shows the presence of $\mathrm{Al}_{3} \mathrm{Mg}_{2}$ in both weld samples. It can be clearly observed that there is $\mathrm{Al}_{3} \mathrm{Mg}_{2}$ in five of the ten diffraction peaks in FSW1 in the diffractogram, mostly in affinity with $\mathrm{Al}$ alloy. This unequivocally confirms the presence of $\mathrm{Al}_{3} \mathrm{Mg}_{2} \mathrm{IMCs}_{\mathrm{Mn}}$ the thick white bands exhibited in the microstructure. The IMCs has high intensity in FSW1 due to the thickness and concentration of white bands compared to the thin white band of few micron meters in FSW2. Furthermore, the IMCs were detected across various degrees across the scan range in FSW1 unlike that of FSW2 where the IMCs are only detected between $32^{\circ}$ and $48^{\circ}$. Figure 9 (b) shows the presence of $\mathrm{Mg}, \mathrm{Al}_{3} \mathrm{Mg}_{2}$ and $\mathrm{AlMg}$ in very low peaks. The lowest diffraction peaks for FSW1 and FSW2 are at $62^{\circ}$ and $48^{\circ}$ while the highest peaks in that same sample order are detected at $35^{\circ}$ and $38^{\circ}$. The high peak intensity of $\mathrm{Al}_{3} \mathrm{Mg}_{2}$ in FSW2, compared to other peaks in the sample could be attributed to the thin white bands containing $\mathrm{Al}_{3} \mathrm{Mg}_{2}$ IMCs in the weld sample, because all other peaks showing the presence of $\mathrm{Al}_{3} \mathrm{Mg}_{2}$ IMCs are relatively low compared to the reference peak. The absence of liquation suggests that the $\mathrm{Al}_{3} \mathrm{Mg}_{2} \mathrm{IMCs}_{\mathrm{M}}$ in the white bands identified in both weld samples occur due to solid-state elemental diffusion, considering the fact that reactive diffusion is very slow in growing the size and thickness of secondary phases [21].
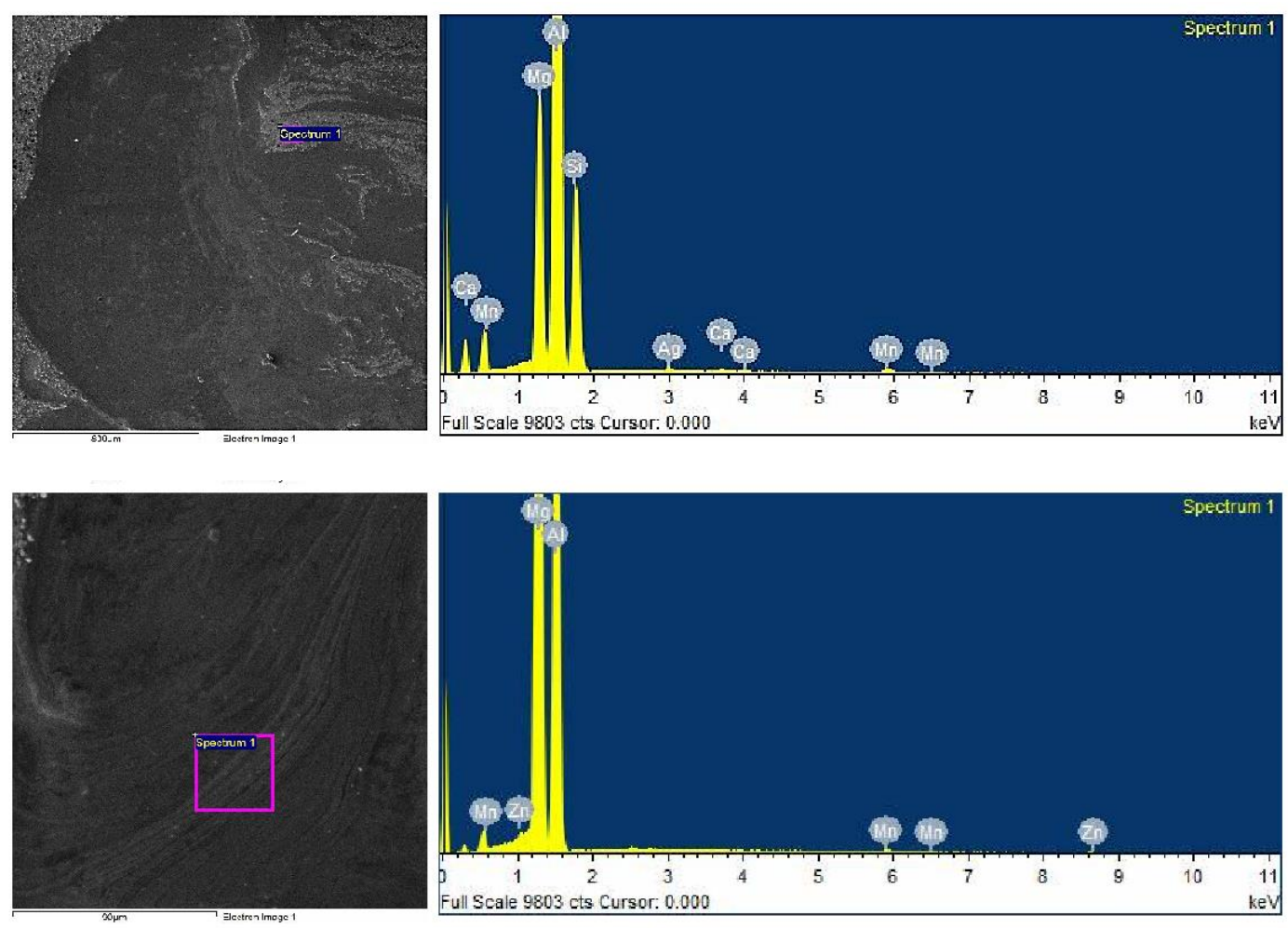

Figure 7. SEM images and EDX analysis of stir zone of FSW1 

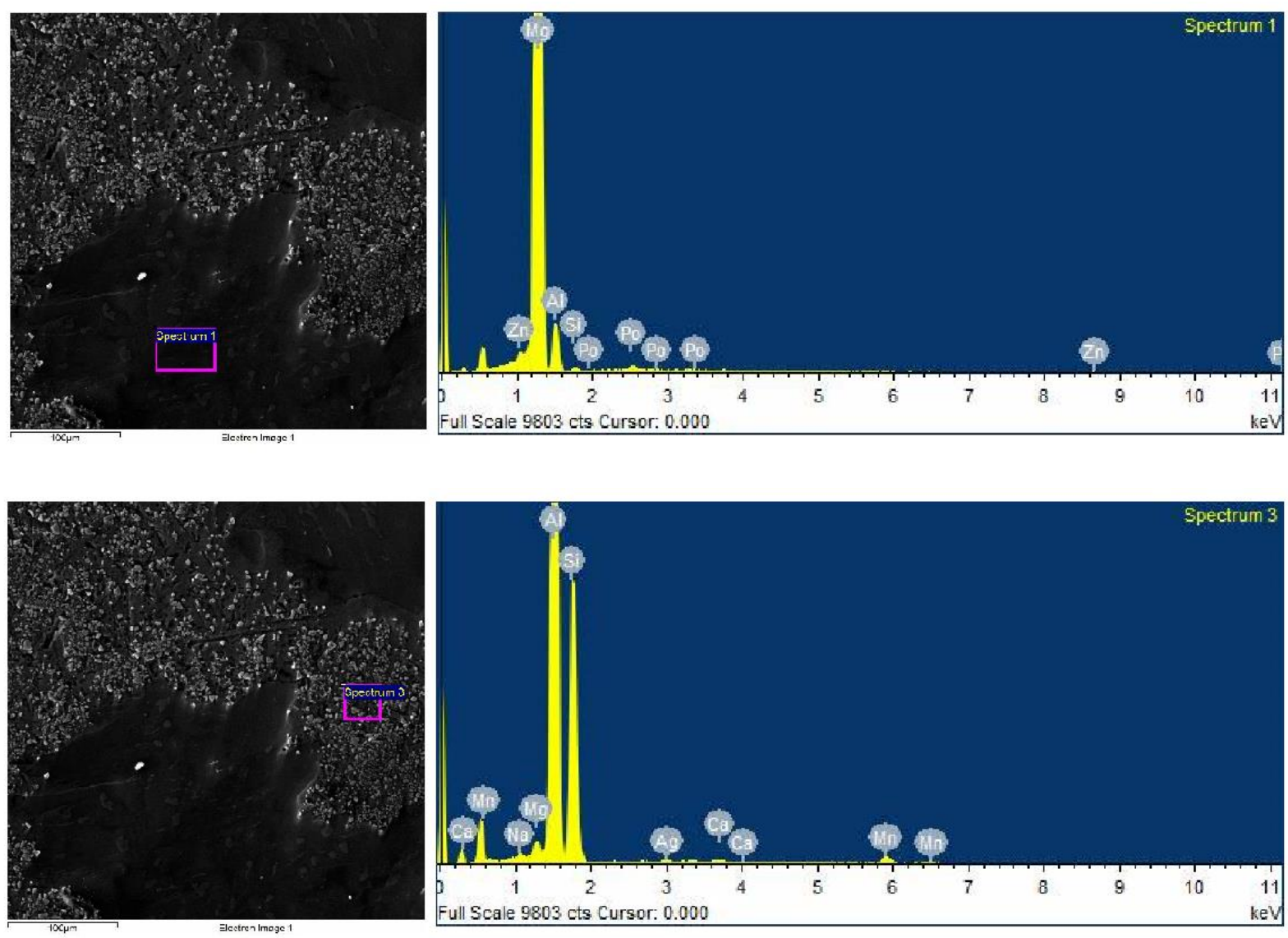

Figure 8. SEM images and EDX analysis of stir zone of FSW2
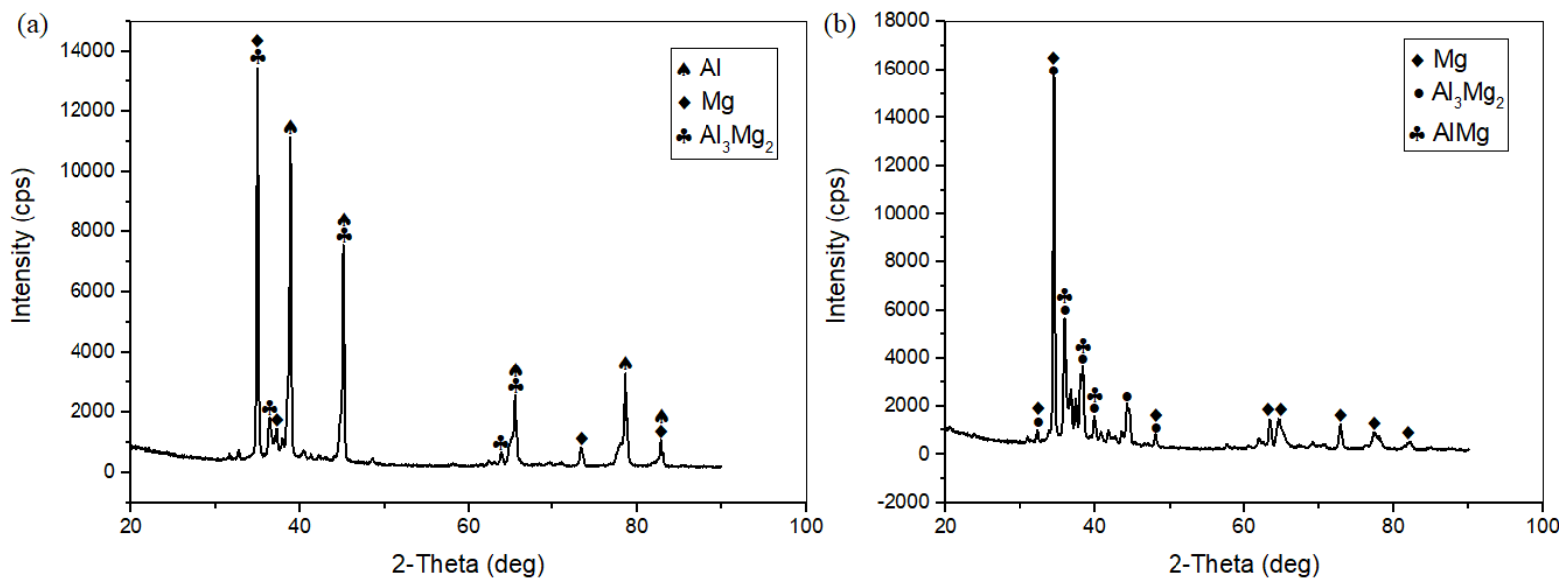

Figure 9. X-ray diffractogram for: (a) FSW1 and (b) FSW2 (Absolute scan between $5^{\circ}$ and $90^{\circ}$ )

\section{Mechanical Characterization}

Figure 10 presents the microhardness profiles of FSW1 and FSW2. The profiles of the samples show an uneven distribution as usually observed in most studies on dissimilar FSW of Mg and Al alloys. The hardness values are plotted from the centre of the stir zone to positions away from the stir zone on both the AS and RS on the weld samples. The hardness distribution show a similar peak hardness values of $141 \mathrm{HV}$ and $139 \mathrm{HV}$ for FSW1 and FSW2 respectively, both on the AS of the weld. The highest hardness value in FSW1 could be attributed to the thick IMCs concentrated in this region as clearly observed in the microstructural characterizations. The high hardness value in FSW2 where there is less IMCs compared to FSW1 could trigger further investigations towards a hypothesis that thick symmetrical IPF may contribute significantly to the hardness value of $\mathrm{Al} / \mathrm{Mg}$ joint. Studies on this phenomenon is scarce and seems to lack researchers' attention based on the authors knowledge as at the time of conducting this study. However, Venkateswaran and Reynolds [29] has reported similar findings when they joined AZ31B and AA6063 using FSW; and observed the presence of IPF in the stir zone, with IMCs on both Mg and Al plates sides. 


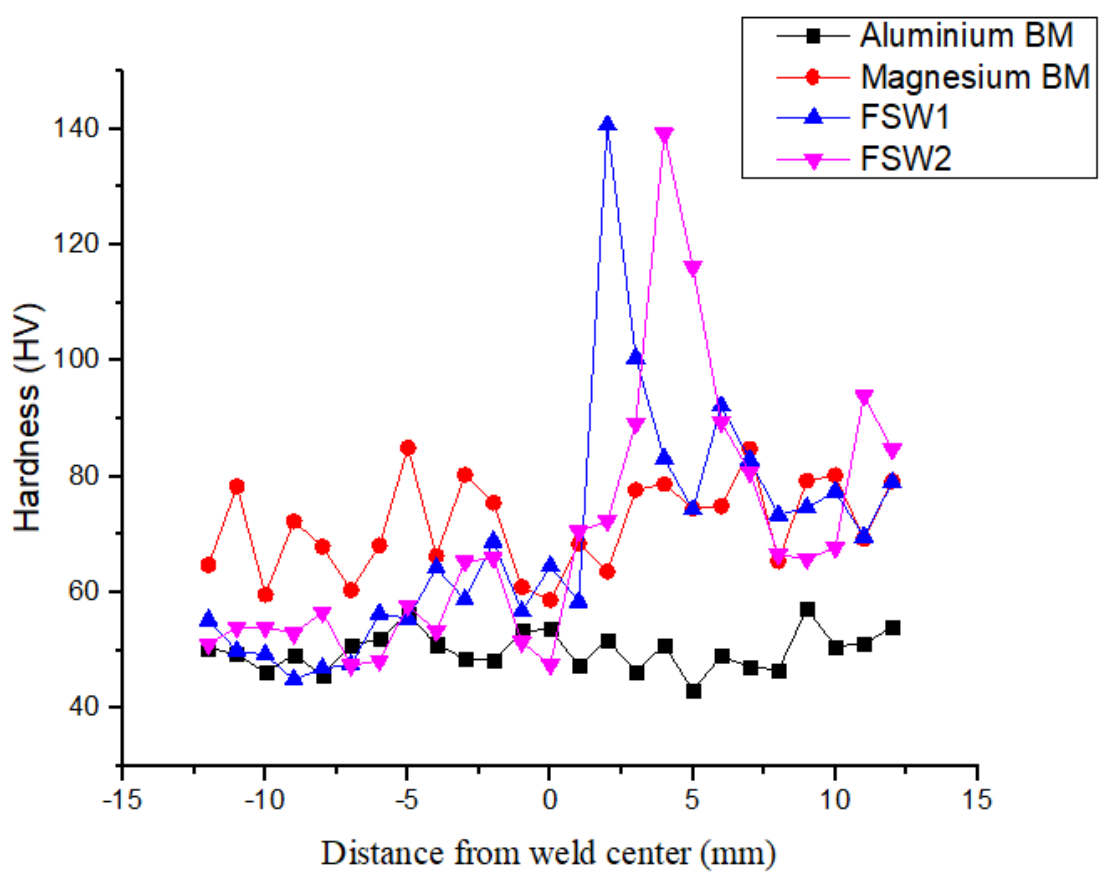

Figure 10. Microhardness profiles of weld samples

Both weld samples exhibit peak hardness values which are identical in range and distribution, and more than double of those of the parent materials. FSW1 and FSW2 has range of hardness values between $45-141 \mathrm{HV}$ and $47-139 \mathrm{HV}$ respectively. The AZ91D and AA1050 parent materials have mean hardness values of $72 \mathrm{HV}$ and $50 \mathrm{HV}$ respectively. This confirms that the weld joints of AZ91D and AA1050 show a similar hardness distribution and mean hardness value at a constant traverse speed of $50 \mathrm{~mm} / \mathrm{min}$ and intermediate rotational speeds of $400 \mathrm{rpm}$ and $600 \mathrm{rpm}$ with the presence of either IMCs or IPF. Figure 11 shows the transverse tensile behavior of FSW1 and FSW2. It can be clearly observed that the two weld samples exhibit different distinct behavior: FSW1 shows an ideal brittle behavior while FSW2 display a combination of brittle behavior with a large quantity of ductile properties. The latter sample shows some plastic deformation characteristics after exceeding the elastic limit, showing a higher strain to fracture and the ability to redistribute localized stresses as opposed to FSW1. AA1050 parent material has superior tensile properties with an average ultimate tensile strength (UTS) of $126 \mathrm{MPa}$ and total percentage elongation of $13 \%$ compared to an average UTS of $117 \mathrm{MPa}$ and elongation of $7 \%$ of the AZ91D parent material.

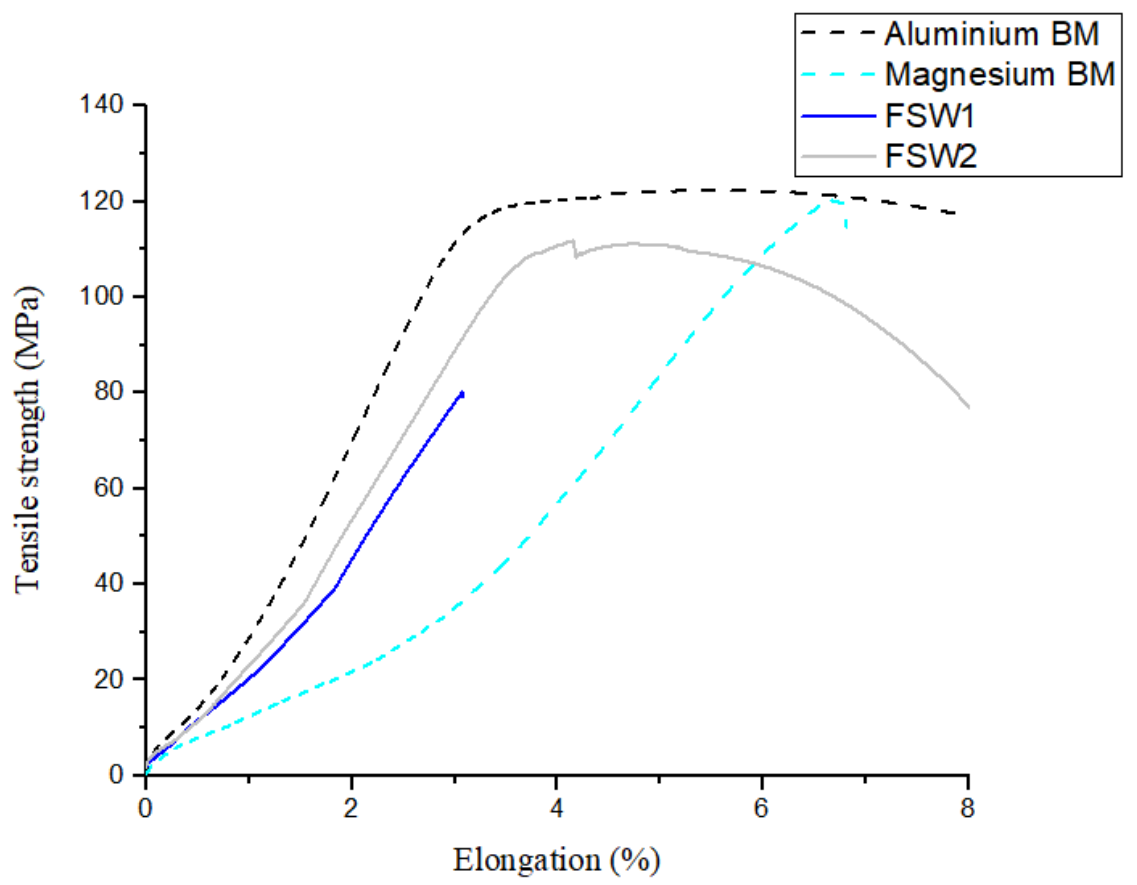

Figure 11. Graph of tensile strength against percentage elongation for weld samples 
The ideal brittle behavior of FSW1 could be attributed to the vast presence of white bands containing $\mathrm{Al}_{3} \mathrm{Mg}_{2} \mathrm{IMCs}_{\mathrm{M}}$. The sample has an average UTS of $69 \pm 4.4 \mathrm{MPa}$ which is significantly lower than the average UTS of both parent materials. On the other hand, FSW2 has an average UTS of $110 \pm 2.5 \mathrm{MPa}$ which is relatively closer to the average UTS of the parent materials. Therefore, the joint efficiency of FSW1 and FSW2 translates to 59\% and 94\% respectively when compared to the average UTS of Mg parent material which possess the least UTS among the parent materials. As clearly observed in the stress-strain behavior of the weld samples, the average total percentage elongation of FSW2 samples surpasses that of FSW1. The former sample has an average total elongation of $8 \%$ while that of the latter sample is only $3 \%$. The significant difference in the ductility can be related to the welds' morphology and presence of IMCs.

The fracture morphology of FSW1 and FSW2 taken from the Mg side of the weld are presented in Figure 12. The absence of local yielding in FSW1 causes the localized stresses to accumulate and eventually causes the initiation and propagation of cracks at the various region of stress concentration before spreading rapidly across the entire cross-section and deteriorating their tensile properties. The cracks undermines the joint integrity and eventually result into the fracture of the weld. On the other hand, the considerably less IMCs and symmetrical IPF in FSW2 aid the distribution of stress among the complex microstructure and hence improved the ductility and UTS. Shah et al [8] reported that this type of joint exhibits optimum material intermixing and are more desirable due to their ability to obstruct crack propagation and high tensile strength. The low ductility in the weld joints of $\mathrm{Mg}$ and $\mathrm{Al}$ alloys have been associated with the formation of brittle IMCs phases present in the joint interface [29].
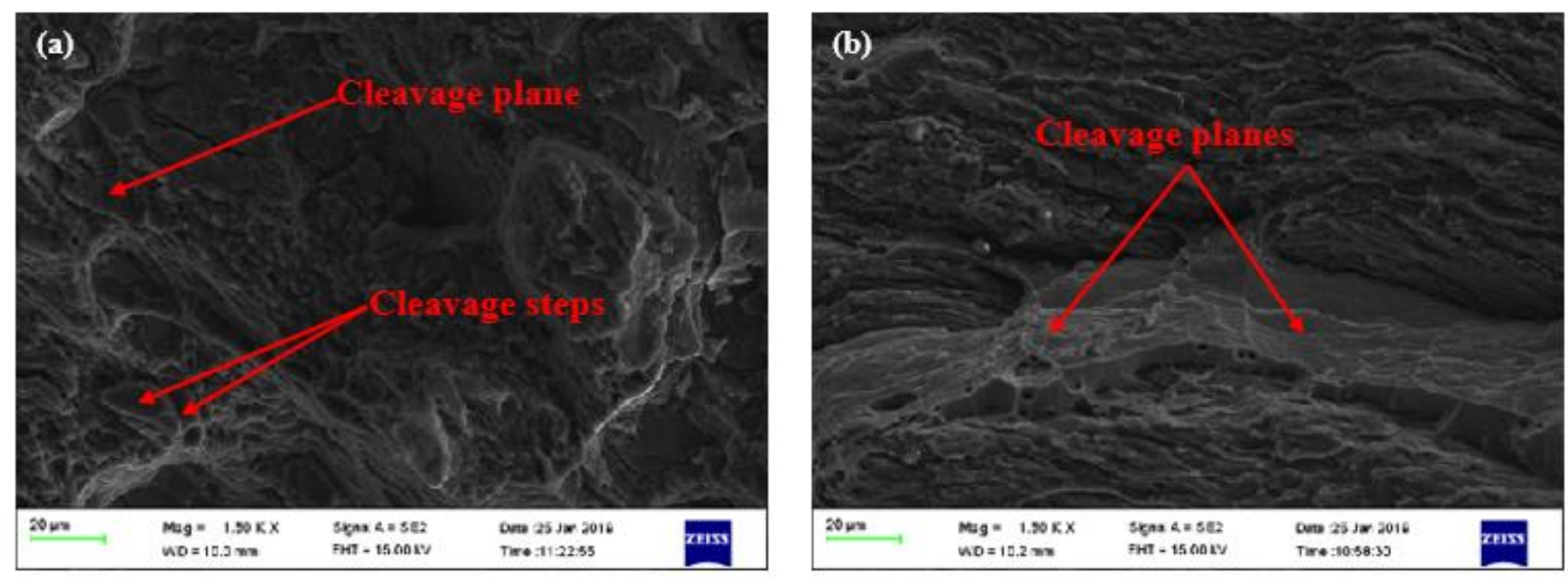

Figure 12. SEM fractographs of the welds' fractured surfaces at 1.50 KX for (a) FSW1 and (b) FSW2

There was a relatively straight line fracture in FSW1, as shown in Figure 13. The fracture surface shows the presence of cleavage planes and steps and confirms that the brittle fracture of the weld is as a result of IMCs concentration towards the AS of the weld. On the contrary, FSW2 shows a zig-zag fracture pattern across the entire IPF. This could be attributed to the thick IPF which creates a wide area of brittle fracture required to cause failure in the weld. The fracture surface of FSW2 also show the presence of similar cleavage features as observed in FSW1 across the fracture path along the IPF, demonstrating mostly brittle fracture characteristics.

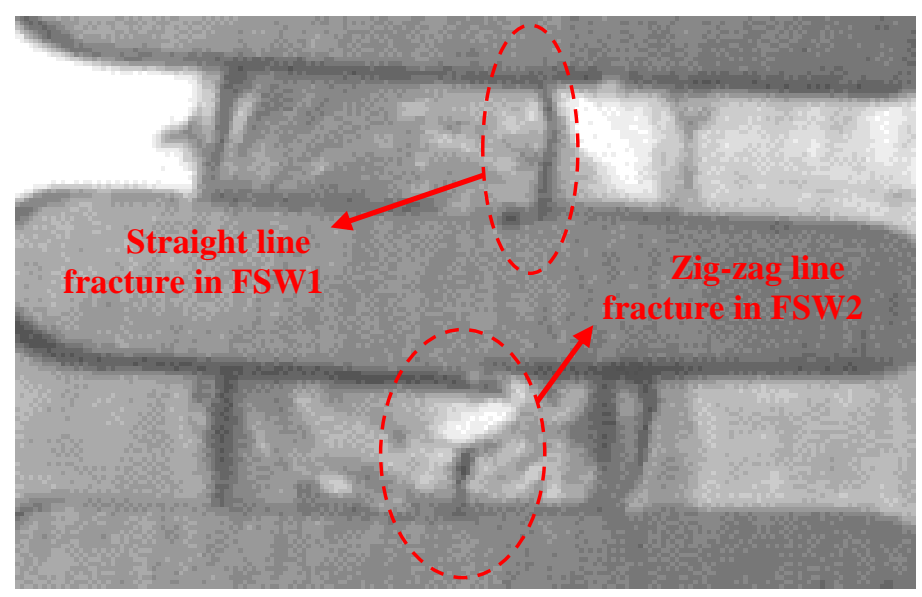

Figure 13. Fracture path of weld samples during tensile testing 


\section{CONCLUSIONS}

In this study, $3 \mathrm{~mm}$ thick AA1050 and AZ91D alloys has been successfully joined with absence of structural defects through friction stir welding within the range of welding conditions employed. Based on the findings, the following conclusions can be drawn:

1) Both weld samples showed a complex intercalated microstructure strongly influenced by the metallurgical bonding, extent of material intermixing and the formation of brittle IMCs.

2) In both welding conditions, $\mathrm{Al}_{3} \mathrm{Mg}_{2}$ IMCs were formed through solid-state diffusion. The IMCs grows with increase in the tool rotational speed as a result of the increase in the amount of frictional heat input.

3) The weld samples' mean hardness values are higher than that of the Al parent material but lesser than the Mg parent material. There was no substantial difference in the mean hardness values of the weld samples. However, the higher peak hardness value in FSW1 compared to FSW2 is due to the formation of thick IMCs.

4) The change in rotational speeds has a significant effect on the tensile strength of the welds, although both weld samples have average UTS lower than those of the parent materials. There was an improvement in the average UTS of FSW2 compared to FSW1 due to the presence of thick symmetrical IPF.

5) The welds produced at a rotational speed of $400 \mathrm{rpm}$ and traverse speed of $50 \mathrm{~mm} / \mathrm{min}$ provided the optimum mechanical properties with limited IMCs.

\section{ACKNOWLEDGMENTS}

The assistance of Dr. M.O. Bodunrin of the School of Chemical and Metallurgical Engineering, University of the Witwatersrand is very much appreciated and acknowledged. The authors acknowledges the support of Prof. S.K Pal, Mr. Suryakanta Sahu and Mr. Debasish Mishra of the Friction Stir Welding Lab, Department of Mechanical Engineering, Indian Institute of Technology (IIT) Kharagpur, India for the provision, comments and assistance with the friction stir welding machine. The corresponding author acknowledges funding support by the University of Johannesburg Global Excellence Stature (GES) for the scholarship award.

\section{REFERENCES}

[1] J. Hirsch, "Aluminium in innovative light-weight car design,” 2011, doi: 10.2320/matertrans.L-MZ201132.

[2] M. Wilhelm, "Materials used in automobile manufacture - current state and perspectives," J. Phys., vol. 3, no. 7 pt 1, pp. 3140, 1993, doi: 10.1051/jp4:1993703.

[3] M. Goede, M. Stehlin, L. Rafflenbeul, G. Kopp, and E. Beeh, "Super Light Car-lightweight construction thanks to a multimaterial design and function integration," Eur. Transp. Res. Rev., 2009, doi: 10.1007/s12544-008-0001-2.

[4] J. J. Michalek, P. Y. Papalambros, and S. J. Skerlos, “A study of fuel efficiency and emission policy impact on optimal vehicle design decisions,” J. Mech. Des. Trans. ASME, vol. 126, no. 6, pp. 1062-1070, 2004, doi: 10.1115/1.1804195.

[5] G. Davies, "Future trends in automotive body materials," in Materials for Automobile Bodies, 2003.

[6] N. Kumar, W. Yuan, and R. S. R. S. Mishra, Friction Stir Welding of Dissimilar Alloys and Materials. 2015.

[7] B. Mansoor, A. Dorbane, G. Ayoub, and A. Imad, "Friction stir welding of AZ31B magnesium alloy with 6061-T6 aluminum alloy: Influence of processing parameters on microstructure and mechanical properties," in Friction Stir Welding and Processing VIII, R. S. Mishra, M. W. Mahoney, Y. Sato, and Y. Hovanski, Eds. Cham: Springer International Publishing, 2016, pp. 259-266.

[8] L. H. Shah, N. H. Othman, and A. Gerlich, "Review of research progress on aluminium-magnesium dissimilar friction stir welding," Sci. Technol. Weld. Join., vol. 23, no. 3, pp. 256-270, 2018, doi: 10.1080/13621718.2017.1370193.

[9] W. M. Thomas, E. D. Nicholas, J. C. Needhan, M. G. Murch, P. Temple-Smith, and C. J. Dawes, "International patent application PCT/GB92/02203 and GB patent application 9125978.8," UK Pat. Off. London, 1991.

[10] D. Lohwasser and Z. Chen, "Introduction,” in Friction Stir Welding: From Basics to Applications, 2009.

[11] M. K. Besharati Givi and P. Asadi, "1 - General introduction BT - Advances in Friction-Stir Welding and Processing," in Woodhead Publishing Series in Welding and Other Joining Technologies, 2014.

[12] N. Yamamoto, J. Liao, S. Watanabe, and K. Nakata, "Effect of intermetallic compound layer on tensile strength of dissimilar friction-stir weld of a high strength Mg alloy and Al alloy," Mater. Trans., vol. 50, no. 12, pp. 2833-2838, 2009, doi: 10.2320/matertrans.M2009289.

[13] Y. S. Sato, S. H. C. Park, M. Michiuchi, and H. Kokawa, "Constitutional liquation during dissimilar friction stir welding of Al and Mg alloys," Scr. Mater., 2004, doi: 10.1016/j.scriptamat.2004.02.002.

[14] B. Fu, G. Qin, F. Li, X. Meng, J. Zhang, and C. Wu, "Friction stir welding process of dissimilar metals of 6061-T6 aluminum alloy to AZ31B magnesium alloy," J. Mater. Process. Technol., 2015, doi: 10.1016/j.jmatprotec.2014.11.039. 
[15] A. Dorbane, B. Mansoor, G. Ayoub, V. C. Shunmugasamy, and A. Imad, "Mechanical, microstructural and fracture properties of dissimilar welds produced by friction stir welding of AZ31B and Al6061," Mater. Sci. Eng. A, 2016, doi: 10.1016/j.msea.2015.11.019.

[16] A. C. Somasekharan and L. E. Murr, "Characterization of complex, solid-state flow and mixing in the friction-stir welding (FSW) of aluminum alloy 6061-T6 to magnesium alloy AZ91D using color metallography," J. Mater. Sci., vol. 41, no. 16, pp. 5365-5370, 2006, doi: 10.1007/s10853-006-0342-y.

[17] A. Masoudian, A. Tahaei, A. Shakiba, F. Sharifianjazi, and J. A. Mohandesi, "Microstructure and mechanical properties of friction stir weld of dissimilar AZ31-O magnesium alloy to 6061-T6 aluminum alloy," Trans. Nonferrous Met. Soc. China (English Ed., 2014, doi: 10.1016/S1003-6326(14)63194-0.

[18] Y. J. Kwon, I. Shigematsu, and N. Saito, "Dissimilar friction stir welding between magnesium and aluminum alloys," Mater. Lett., vol. 62, no. 23, pp. 3827-3829, 2008, doi: 10.1016/j.matlet.2008.04.080.

[19] Y. Yan, D. T. Zhang, C. Qiu, and W. Zhang, "Dissimilar friction stir welding between 5052 aluminum alloy and AZ31 magnesium alloy," Trans. Nonferrous Met. Soc. China (English Ed., 2010, doi: 10.1016/S1003-6326(10)60550-X.

[20] V. Firouzdor and S. Kou, "Al-to-Mg friction stir welding: Effect of material position, travel speed, and rotation speed," Metall. Mater. Trans. A Phys. Metall. Mater. Sci., vol. 41, no. 11, pp. 2914-2935, 2010, doi: 10.1007/s11661-010-0340-1.

[21] V. Firouzdor and S. Kou, "Formation of liquid and intermetallics in Al-to-Mg friction stir welding," Metall. Mater. Trans. A Phys. Metall. Mater. Sci., vol. 41, no. 12, pp. 3238-3251, 2010, doi: 10.1007/s11661-010-0366-4.

[22] ASTM E384-05a, "Standard Test Method for Microindentation Hardness of Materials," ASTM Int., vol. 14, pp. 1-24, 2005, doi: 10.1520/E0384-05A.

[23] A. Standard, "E8/E8M-13a," Stand. Test Methods Tens. Test. Met. Mater. ASTM Int. West Conshohocken, PA, 2013.

[24] C. G. Rhodes, M. W. Mahoney, W. H. Bingel, R. A. Spurling, and C. C. Bampton, "Effects of friction stir welding on microstructure of 7075 aluminum," Scr. Mater., 1997, doi: 10.1016/S1359-6462(96)00344-2.

[25] Y. S. Sato, H. Kokawa, M. Enomoto, and S. Jogan, "Microstructural evolution of 6063 aluminum during friction-stir welding," Metall. Mater. Trans. A Phys. Metall. Mater. Sci., vol. 30, no. 9, pp. 2429-2437, 1999, doi: 10.1007/s11661-999-0251-1.

[26] M. A. Mofid, A. Abdollah-Zadeh, and F. M. Ghaini, "The effect of water cooling during dissimilar friction stir welding of Al alloy to Mg alloy,” Mater. Des., vol. 36, pp. 161-167, 2012.

[27] X. Meng, Y. Jin, S. Ji, and D. Yan, "Improving friction stir weldability of Al/Mg alloys via ultrasonically diminishing pin adhesion,” J. Mater. Sci. Technol., vol. 34, no. 10, pp. 1817-1822, 2018, doi: 10.1016/j.jmst.2018.02.022.

[28] H. Shi et al., "Intermetallic compounds in the banded structure and their effect on mechanical properties of Al/Mg dissimilar friction stir welding joints," J. Mater. Sci. Technol., vol. 33, no. 4, pp. 359-366, 2017, doi: 10.1016/j.jmst.2016.05.006.

[29] P. Venkateswaran and A. P. Reynolds, "Factors affecting the properties of friction stir welds between aluminum and magnesium alloys," Mater. Sci. Eng. A, vol. 545, pp. 26-37, 2012, doi: 10.1016/j.msea.2012.02.069.

[30] Y. C. Chen and K. Nakata, "Friction stir lap joining aluminum and magnesium alloys," Scr. Mater., 2008, doi: 10.1016/j.scriptamat.2007.10.033. 